\title{
La Unidad Médica de Aeroevacuación
}

La aeroevacuación médica es un eslabón más de la cadena asistencial que permite mejorar el pronóstico vital a corto plazo y funcional a largo plazo de un paciente, realizada con personal y equipo especializado, su misión última es trasladar pacientes desde una formación sanitaria a otra más adecuada para las características de su patología, manteniendo los cuidados asistenciales en vuelo y subordinando su acción al medio aeronáutico con las limitaciones que ello impone.

Las primeras misiones de aeroevacuación médica en España tuvieron lugar en el año 1917 en Marruecos; en la guerra civil se creó el primer escuadrón de ambulancias aeromedicalizadas, si bien no es hasta el año 1989, en la misión de Namibia UNTAG, en el que se cambia el concepto asistencial y se diseñan los equipos de aeroevacuación formados por un médico, un enfermero y un técnico, todos ellos con conocimientos de medicina aeronáutica. A partir de 1990 los conflictos de los Balcanes, Afganistán e Irak desarrollan este concepto y convierten ese equipo en un grupo multidisciplinar formado por médicos de diferentes especialidades y enfermeros, todos ellos destinados en el Hospital del Aire.

El 6 de febrero de 2003 se creó la UMAER, Unidad Médica de Aeroevacuación, para dar adecuada respuesta a los retos derivados de la participación española en conflictos armados lejos de nuestro territorio y el manejo de las bajas generadas en ellos, que precisaran su traslado a Territorio Nacional por vía aérea. En febrero de 2015 la UMAER se ha integrado en el EATC (European Air Transport Comand), lo cual confiere a la actividad propia de la Unidad un mayor tinte internacional y de cooperación con el resto de países de nuestro entorno militar.

La UMAER actual es la segunda Unidad más pequeña del Ejército del Aire. Consta de 21 miembros, entre ellos, cuatro médicos de vuelo y cuatro enfermeros de vuelo, el resto está constituido por técnicos sanitarios y suboficiales necesarios para el funcionamiento de la Unidad desde el punto de vista organizativo y de función militar.

La doctrina asistencial que sigue, fruto de la experiencia adquirida en más de 25 años de actividad desde el inicio en el Hospital del Aire, y se basa en unos principios, expresados en diferentes STANAGs de la OTAN, documentos nacionales y organizaciones multinacionales:

1. Prestar una asistencia sanitaria tan rápida y eficaz en Zona de Operaciones como la que los combatientes tienen en Territorio Nacional.

2. En la cadena de evacuación el nivel asistencial debe aumentar de manera continua y debe ser igual o mejor que la que se prestaba en el escalón sanitario anterior, incluso durante la evacuación.

3. La asistencia sanitaria prestada debe ser cualificada, con los medios técnicos adecuados y con el personal entrenado específicamente para ello, adelantando procedimientos asistenciales que optimicen tratamientos posteriores. La aeroevacuación no debe basarse únicamente en trasladar al herido desde el lugar del incidente hasta el hospital.
Hoy en día, las misiones de la UMAER incluyen la aeroevacuación de bajas desde donde éstas se hayan producido hasta la formación sanitaria más adecuada y la intervención inmediata en situaciones de emergencia para realizar un triage y puesta en condiciones de aeroevacuación de las bajas que lo necesiten.

Para dar respuesta a estas necesidades, es preciso:

- Una organización adecuada capaz de realizar un despliegue rápido, con suficiente autonomía, y de adaptarse a los eventos inesperados manteniendo su completa operatividad funcional.

- Mejorar las capacidades asistenciales de los medios humanos y aeronáuticos disponibles.

- Aumentar los niveles de competencia de las tripulaciones sanitarias.

- Manejar equipos adecuados a estas necesidades.

Para ello, la UMAER se constituye en una fuerza de proyección de muy alta disponibilidad, que en un periodo aproximado de 2 horas, debe ser capaz de desplegar los medios asistenciales que considere necesario para cada paciente.

El carecer de aeronaves dedicadas específicamente a las misiones MEDEVAC ha permitido desarrollar una capacidad que es una de las características más destacadas de la Unidad: la flexibilidad.

La Unidad debe ser capaz de, conociendo y valorando la patología que presenta el paciente, el tratamiento aplicado y su estado clínico, determinar las características de la aeronave más adecuada para realizar el traslado, la composición del equipo asistencial, los medios técnicos idóneos y prever las posibles complicaciones, tanto puramente asistenciales como las derivadas del propio medio en el que se desarrolla la misión, así como los imprevistos que se puedan presentar en el vuelo debidos a la aeronave, a la climatología o a la ruta empleada. Por todo ello, el personal destinado debe tener:

1) Conocimientos clínico asistenciales actualizados.

2) Conocimientos de los medios técnicos, no sólo en su funcionamiento sino también en los métodos para integrarlos en la aeronave sin interferir en su funcionamiento ni en la seguridad del vuelo.

3) Conocimientos de las características del medio aeronáutico, de las leyes físicas que lo gobiernan y de su composición, así como la repercusión que todo ello (hipoxia, disbarismos, aceleraciones, baja humedad, ruidos, vibraciones, radiaciones, etc) provoca en el paciente, tomando las medidas necesarias para impedir o minimizar sus efectos adversos.

4) Conocimientos de las aeronaves y sus características, con el fin de solicitar al Mando Aéreo de Combate, mando operativo de la Unidad, la más adecuada para cada aeroevacuación.

La aparición de la epidemia de gripe aviar producida por el virus H5N1 en Hong Kong en 1997 que afectó a 18 personas, con una mortalidad del 33\%, su reaparición en 2003, confirmándose casos hasta 2005 en el Lejano Oriente, con una mortalidad del 50\%, y 


\section{Editorial}

en Europa, junto con la posibilidad de expansión por las aves migratorias, puso en evidencia la necesidad de trabajar con medidas de aislamiento individual para prevenir el contagio. Recientemente, el último brote de Ébola en África y la necesidad de previsión de evacuación de pacientes infectados al Territorio Nacional, supuso un desafío al que se hizo frente con los medios disponibles, que confirmaron ser adecuados.

Las lecciones aprendidas en cuanto a lo específico de un traslado de pacientes con enfermedad transmisible, sobre todo en una patología como es la del virus Ébola, rodeado de gran alarma social, fueron muchas y nos llevaron a la confección de protocolos de actuación en estos casos que hoy en día son seguidos por las Unidades de MEDEVAC de todo el mundo. Destacando la previsión de material sanitario y equipos específicos, el entrenamiento apropiado del personal que maneja estos equipos y al paciente, la integración de procedimientos con el personal de los grupos aéreos y la finalización correcta con gestión de residuos y desinfección de equipos y áreas de trabajo. Cobró especial relevancia el registro y documentación de los casos, así como la comunicación con instituciones civiles.

Ahora mismo nuestra Unidad se enfrenta a una nueva forma de actuación, que viene impuesta por la integración en el EATC, con nuevas directrices, nuevo organigrama, diferente manera de manejar la información, mayor dependencia de comunicaciones en otros idiomas y nuestra integración en tripulaciones médicas multinacionales; todo ello supone un nuevo reto que obliga a una adaptación de procedimientos previos. Esto, en sí, ya supone el presente y el futuro de nuestra Unidad que sigue esforzándose para mantener y elevar el nivel médico y de servicio que siempre ha sido característica de la Sanidad Militar Española.

\section{Zacarías Galo Sánchez Sánchez}

Teniente Coronel Médico Jefe de la Unidad de Aeroevacuación del Ejército del Aire

(UMAER)

Base aérea de Torrejón. Torrejón de Ardoz. Madrid 